\title{
Instrumental perforations of the oesophagus and their
} management

\author{
K MOGHISSI, D PENDER \\ From Humberside Cardiothoracic Surgical Centre, Castle Hill Hospital, Cottingham, North Humberside
}

\begin{abstract}
The records of 39 patients who had developed a perforation of the oesophagus after instrumentation were reviewed. Ten (group A) had cervical and 29 (group B) thoracic oesophageal perforation. Twenty three perforations occurred during dilatation of an oesophageal stricture, 10 during oesophagoscopic removal of a foreign body, and six during diagnostic oesophagoscopy. Of the 21 patients treated within 36 hours (early treatment group), four (19\%) died; of the 18 treated more than 36 hours after the perforation (late treatment group), nine (50\%) died. None of the 10 patients in group A had strictures and only two presented late. After drainage of the neck and mediastinum the outcome was successful in all patients. Thirteen of the 29 in group B were treated early and four of these died; nine of the 16 treated late died, the total mortality for thoracic perforation being $48 \%$. An oesophageal stricture was present in 23 patients. Twelve of these underwent various forms of conservative surgery and there were 10 deaths. This contrasts with the 11 who received radical treatment with resection and reconstruction, only two of whom died. The six patients with no pre-existing stricture were treated with conservative forms of surgery, with one death.
\end{abstract}

\section{Introduction}

The expansion of diagnostic and therapeutic endoscopy has resulted in an increased number of instrumental perforations of the oesophagus, some of which occur in departments with no surgical expertise or facilities at hand. As a result, the surgeon often has to deal with a perforation at a late stage and sometimes after failure of initial treatment. Although the importance of early recognition of instrumental perforation is widely acknowledged, ${ }^{1-8}$ its management remains controversial. One reason for this is that many papers ${ }^{1-35-7910}$ have described heterogeneous groups of patients, with perforation occurring after oesophageal operation and intubation, instrumentation, and injury, and management differs in these different circumstances.

The purpose of this paper is to review a series of patients with rupture of the oesophagus due solely to diagnostic or therapeutic oesophagoscopy. Rupture caused by oesophageal intubation of malignant obstruction is excluded from the review.

Address for reprint requests: Mr K Moghissi, Humberside Cardiothoracic Surgical Centre, Castle Hill Hospital, Cottingham, North Humberside, HU16 5JQ.

Accepted 5 May 1988

\section{Patients and methods}

\section{PATIENTS}

During the 15 years 1970-84 39 patients with instrumental perforations of the oesophagus were admitted from five district general hospitals to the $\underset{\times}{\stackrel{\Xi}{\Perp}}$ Humberside Cardiothoracic Surgical Centre under $\frac{0}{5}$ one surgeon (KM). We reviewed the hospital records of these patients. Patients were divided into two o groups according to the site of perforation, group $\mathrm{A}$ having a cervical and group B a thoracic oesophageal 음 perforation. The aetiology of the perforation and the type of oesophagoscope used, whether rigid or flexible fibreoptic, was recorded. The time lapse between $\vec{\sim}$ oesophagoscopy and diagnosis of perforation was $\sigma$ recorded for each case and the perforation was then 0 classified as "early" in presentation (up to 36 hours) or స్ "late" (more than 36 hours). The prominent symp- ㅇ toms and signs for each patient were noted. The 0

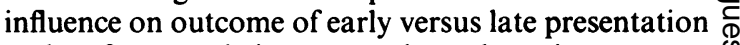
and of pre-existing oesophageal stricture was $\stackrel{\odot}{+}$ examined. Finally, the results of various forms of 0 conservative and radical surgical procedures were assessed.

TREATMENT

All patients received appropriate antibiotics and 
parenteral feeding with high calorie and nitrogen content for varying lengths of time. Initial intravenous feeding was followed by combined parenteral and enteral nutrition progressing to total enteral feeding, and finally, for those who survived, to oral food intake. Parenteral feeding was provided via a central venous catheter using the percutaneous subclavian route or an external jugular vein incision with subcutaneous tunnelling. " Enteral nutrition was given by gastrostomy for cervical perforations and through a fine tube jejunostomy for thoracic perforations. ${ }^{12}$

Conservative surgical treatment consisted of $(a)$ drainage of the neck and mediastinal or pleural space (or both); (b) repair of the perforation and drainage; (c) repair of the perforation and total fundoplication. Radical surgical treatment consisted of resection and reconstruction of the oesophagus.

Analysis of statistical significance was performed by means of Fisher's exact probability test.

\section{Results}

Twenty three of the 39 perforations occurred during dilatation of strictures, 10 during oesophagoscopic removal of a foreign body and six during diagnostic

Table 1 Symptoms and signs of perforations of the oesophagus: numbers of patients

\begin{tabular}{|c|c|c|c|c|}
\hline & \multicolumn{2}{|c|}{$\begin{array}{l}\text { Group } A \\
(n=10)\end{array}$} & \multicolumn{2}{|c|}{$\begin{array}{l}\text { Group } B \\
(n=29)\end{array}$} \\
\hline & $\begin{array}{l}\text { Early } \\
(8)\end{array}$ & $\begin{array}{l}\text { Late } \\
\text { (2) }\end{array}$ & $\begin{array}{l}\text { Early } \\
\text { (13) }\end{array}$ & $\begin{array}{l}\text { Late } \\
(16)\end{array}$ \\
\hline \multicolumn{5}{|l|}{ Symptoms } \\
\hline Sore throat & 8 & 1 & 13 & 6 \\
\hline Pain & 8 & 1 & 13 & 7 \\
\hline Dyspnoea & 0 & 0 & 9 & 16 \\
\hline $\begin{array}{l}\text { Dysphagia } \\
\text { Signs }\end{array}$ & 8 & 2 & 12 & 12 \\
\hline $\begin{array}{l}\text { Surgical subcutaneous } \\
\text { emphysema (neck) }\end{array}$ & 4 & 0 & 5 & 0 \\
\hline Cellulitis (neck) & 4 & 1 & 1 & 0 \\
\hline Pneumothorax & 0 & 0 & 8 & 16 \\
\hline Pleural effusion & 0 & 0 & 4 & 16 \\
\hline Fever & 3 & 2 & 5 & 15 \\
\hline Shock & 1 & 0 & 1 & 5 \\
\hline \multicolumn{5}{|l|}{ Radiology } \\
\hline $\begin{array}{l}\text { Cervical surgical } \\
\text { emphysema }\end{array}$ & 8 & 0 & 9 & 4 \\
\hline $\begin{array}{l}\text { Neckspace fluid } \\
\text { collection }\end{array}$ & 4 & 1 & 0 & 1 \\
\hline Mediastinal emphysema & 3 & 2 & 12 & 6 \\
\hline Pneumothorax & 0 & 0 & 12 & 16 \\
\hline Pneumoperitoneum & 0 & 0 & 3 & 0 \\
\hline Mediastinal abscess & 3 & 1 & 5 & 3 \\
\hline $\begin{array}{l}\text { Hydrothorax or } \\
\text { pyothorax }\end{array}$ & 0 & 1 & 9 & 16 \\
\hline $\begin{array}{l}\text { Pulmonary abscess } \\
\text { Positive result of barium } \\
\text { study* }\end{array}$ & $\begin{array}{l}0 \\
3(3)\end{array}$ & $\begin{array}{l}1 \\
2(2)\end{array}$ & $\begin{array}{l}0 \\
13(13)\end{array}$ & $\begin{array}{l}2 \\
16(16)\end{array}$ \\
\hline \multicolumn{5}{|l|}{ Endoscopy* } \\
\hline Positive result & $8(8)$ & $2(2)$ & $6(6)$ & $11(11)$ \\
\hline
\end{tabular}

*Parentheses indicate the number of patients on whom the investigation was performed. oesophagoscopy. Apart from perforations associated with removal of a foreign body, for which the rigid oesophagoscope was used exclusively, perforations occurred with both the rigid and the flexible oesophagoscope.

The prominent symptoms and signs of "early" and "late" perforations for each group of patients are summarised in table 1 . Pain and dysphagia were frequent. Subcutaneous surgical emphysema, pneumomediastinum, or pneumothorax were seen on the radiographs of all patients. Pyopneumothorax or mediastinal abscesses were seen in those with a late presentation. Contrast studies using Gastrografin or Dionosil helped to identify the site of perforation in the 34 patients who underwent the procedure. In three patients the mucosal perforation was $4-8 \mathrm{~cm}$ above the site of oesophageal muscular rupture, showing the presence of a dissection of the oseophagus. Endoscopy, carried out in 27 patients, in all cases identified the site of perforation and the underlying oesophageal lesion.

There were 13 deaths in the 39 subjects, an overall mortality of $33 \%$. Delay in presentation had an adverse effect on outcome (table 2), with four deaths $(19 \%)$ among the 21 patients presenting early and nine deaths $(50 \%)$ among the 18 presenting late $(\mathrm{p}<0.05)$.

GROUP A: PERFORATION OF CERVICAL OESOPHAGUS

Ten patients (six of them female), aged 18-74 (mean 42) years, had a perforation of the cervical oesophagus, eight of them presenting within 36 hours of perforation. Rigid oesophagoscopy for removal of a foreign body was the most common cause (seven cases); the remaining three occurred during diagnostic oesophagoscopy - two with the flexible fibreoptic and one with the rigid oesophagoscope.

All patients complained of dysphagia and nine had pain (table 1). Radiography showed cervical surgical emphysema in eight, mediastinal emphysema in five, and a mediastinal abscess in four patients. An emergency contrast swallow in five patients showed the perforation in each case. Endoscopy was performed in

Table 2 Relation between delay in treatment and survival*

\begin{tabular}{llll}
\hline & \multicolumn{3}{l}{ Number of patients treated } \\
\cline { 2 - 4 } & $\begin{array}{l}\text { Early } \\
(n=21)\end{array}$ & $\begin{array}{l}\text { Late } \\
(n=18)\end{array}$ & $\begin{array}{l}\text { Total } \\
(n=39)\end{array}$ \\
\hline $\begin{array}{c}\text { Group A } \\
(\mathrm{n}=10)\end{array}$ & $8[0]$ & $2[0]$ & $10[0]$ \\
$\begin{array}{c}\text { Group B } \\
(\mathrm{n}=29)\end{array}$ & $13[4]$ & $16[9]$ & $29[13]$ \\
Overall & $21[4]$ & $18[9]$ & $39[13]$ \\
\hline
\end{tabular}

*Square brackets denote the number of patients who died. 
Table 3 Influence of pre-existing stricture and the mode of treatment on survival of patients with thoracic oesophageal perforation (group B)

\begin{tabular}{|c|c|c|c|c|}
\hline & \multicolumn{4}{|c|}{ No of patients } \\
\hline & \multicolumn{2}{|c|}{ With stricture } & \multicolumn{2}{|c|}{ Without stricture } \\
\hline & Treated & Died & Treated & Died \\
\hline $\begin{array}{l}\text { Drainage } \\
\text { Repair and drainage } \\
\text { Repair and } \\
\text { fundoplication }\end{array}$ & $\begin{array}{l}3 \\
6 \\
3\end{array}$ & $\begin{array}{l}3 \\
6 \\
1\end{array}$ & $\begin{array}{l}2 \\
2 \\
2\end{array}$ & $\begin{array}{l}1 \\
0 \\
0\end{array}$ \\
\hline $\begin{array}{l}\text { Resection and } \\
\text { reconstruction }\end{array}$ & 11 & 2 & 0 & 0 \\
\hline
\end{tabular}

all patients to assess the size of the perforation and the degree of surrounding induration.

Surgical drainage of the cervical fascial spaces was undertaken in all cases. In six drainage was confined to the neck spaces alone, but in three in whom medical treatment had failed both the neck and the superior mediastinum were drained. In one patient, admitted some days after perforation, mediastinal and pulmonary abscesses in addition to the neck spaces required drainage; this was a first step in a multistage procedure that subsequently included a limited thoracoplasty. All patients in this group recovered.

GROUP B: PERFORATION OF THORACIC OESOPHAGUS

Twenty nine patients ( 23 of them female), aged 5-74 (mean 57) years, had thoracic perforations. The cause was dilatation of a stricture in 23, 12 occurring with the rigid and 11 with the fibreoptic instrument. In three patients perforation occurred during extraction of a foreign body with the rigid oesophagoscope and in three during diagnostic oesophagoscopy (with the flexible fibreoptic oesophagoscope in two cases).

Dysphagia and pain were the most common symptoms. All patients presenting early had severe pain in the chest or upper abdomen, compared with less than half of those presenting late. Pneumothorax, pleural effusion, and pyothorax were common (table 1). Overall, 13 of the 29 patients $(44 \%)$ in group B died. Four deaths occurred among the 13 "early" presentations and nine in the 16 "late" presentations (NS).

Six patients in this group had no stricture. All were managed by conservative surgery-by means of drainage, repair, or fundoplication - and five of the six survived (table 3 ).

Of the 23 patients with a pre-existing stricture, 11 underwent resection and reconstruction. This was undertaken as a two stage procedure in two patientsboth referred, after failure of medical treatment, with an extensive oesophageal tear and severe mediastinitis. Excision of the thoracic oesophagus with cervical oesophagostomy and feeding gastrostomy was carried out as the first stage, followed by oesophagocoloplasty $\vec{\Rightarrow}$ three and six months later. There were two deaths $\stackrel{0}{+}$ among these 11 patients. Six patients underwent repair of the perforation and drainage and three underwent $\overline{\bar{D}}$ drainage alone; all nine patients died. Repair of the $\frac{\bar{T}}{\vec{D}}$ perforation and total fundoplication was carried out $\stackrel{\mathbb{Q}}{\Omega}$ in three patients, one of whom died.

There was no significant difference in mortality $\vec{O}$ between the 23 patients with a stricture ( 12 deaths) and the six patients without (one death). The effect of $\vec{\omega}$ treatment method, however, did depend on whether a $\stackrel{\circ}{\rightarrow}$ stricture was present. Repair with drainage or fundo- $\vec{x}$ plication or drainage alone yielded good results in the absence of a stricture (five of six patients survived), but 9 when a stricture was present 10 of the 12 patients died. os Patients with a stricture treated with resection and $\vec{N}$ reconstruction of the oesophagus fared better and only two of the 11 patients died ( $p<0.01$ in comparison $\vec{x}$ with conservative surgery).

\section{Discussion}

The incidence of instrumental perforations of the oesophagus is reported to be from $0.018 \%$ to $1.9 \%{ }^{4-61314}$ This wide range is related to several factors, such as the type of oesophagoscope used, the $\bar{\partial}$ skill of the operator, and most of all the variation in the patients studied. In all series the incidence of $\mathscr{\mathbb { Q }}$ perforation is higher for endoscopic dilatation of $\overrightarrow{\overrightarrow{0}}$ strictures than for oesophagoscopy carried out to 3 extract foreign bodies or for diagnosis. This is reflected $\vec{F}$ in our series, where most of the perforations resulted from endoscopic dilatation of oesophageal strictures.

It has been suggested ${ }^{15}$ that a fibreoptic oeso- $O$ phagogastroscope and Eder Puestow dilator for stric- $\underset{x}{x}$ ture dilatation is less hazardous than a rigid oeso- $\frac{O}{3}$ phagoscope. We can find no firm evidence to support this claim; in our study there were almost as many 0 perforations with the fibreoptic as with the rigid

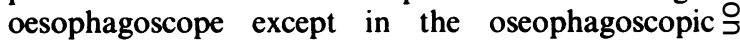
removal of foreign bodies, for which the rigid oeso- $\rightarrow$ phagoscope is used exclusively. But as the overall number of oesophagoscopies carried out with each $\tilde{N}^{-}$ type of oesophagoscope is unknown the incidence of perforations related to either instrument cannot be 0 assessed. There is nevertheless a definite risk of $\omega$ perforation from any oesophagoscopy procedure, particularly when associated with dilatation of ac stricture, irrespective of the type of oesophagoscope $\mathbb{D}$ used.

Several authors ${ }^{1357910}$ have pointed to the impor- $\frac{0}{3}$ tance of early diagnosis and prompt treatment of a $\frac{\vec{D}}{\mathbb{D}}$ perforation for the patient's survival. Our study $\stackrel{?}{\mathbb{Q}}$ confirms this and also indicates that outcome depends $\stackrel{\mathbb{Q}}{\perp}$ on other factors, notably the location of the perforation and whether an oesophageal stricture is present. 
Most oesophageal perforations occur during endoscopic dilatation of a stricture or extraction of a foreign body. As a thoracic oesophageal perforation cannot always be diagnosed clinically at an early stage, we believe that a plain chest and neck radiograph should be taken two to three hours after oesophageal dilatation and after the extraction of a retained foreign body from the oesophagus, before food is allowed. Once the diagnosis of perforation is made it is important to locate the site of the rupture and to identify oesophageal lesions as both are relevant to management. Contrast radiography using Dionosil will indicate the site of perforation and the existence of an obstructive lesion of the oesophagus. The investigation is mandatory for patients who have not had a barium swallow before oesophagoscopy. When the point of mucosal break and the outer muscular perforations of the oesophagus are some distance from each other because of oesophageal dissections, as in three of our patients, endoscopy is particularly important in determining the characteristics of the perforation and of the oesophagus.

Although there is general acceptance that the prognosis for patients with oesophageal perforation is largely dependent on early treatment, there is controversy about the best course of treatment in particular circumstances - especially about the need for surgical treatment, given the availability of potent antibiotics and advanced nutritional techniques. Proponents of a conservative approach ${ }^{5616}$ suggest that prompt withdrawal of oral food and fluid, administration of antibiotics, and parenteral (or enteral) nutrition will be successful. The advocates of surgical treatment ${ }^{1-391718}$ believe that, in the presence of continuing mediastinitis and a mediastinal abscess or an established pyopneumothorax, the conservative medical approach contravenes accepted surgical principles and is bound to fail. They point out that some "failed medically treated cases" have to be submitted to surgical operations, for which they are high risk candidates. Some of these differences appear to be due to a lack of appreciation that different studies have been concerned with different types of patients, and that some series include patients with oesophageal perforations occurring during or after oesophageal intubation for malignancy. Others, like ourselves, believe that these perforations should be viewed separately as they present different problems. The term conservative treatment may also have caused confusion as it has been used by some to indicate medical treatment and by others to cover drainage procedures.

Most investigators agree that a cervical perforation recognised early can be successfully treated conservatively, and this was the case for eight of our patients with a cervical perforation. In chronic cervical perforation, however, with a purulent collection tracking into the mediastinum medical treatment is unlikely to succeed. Unless the perforation is insignificant and discovered very early, we advocate simple drainage of the neck space in addition to medical treatment. More elaborate surgery is rarely needed.

With thoracic oesophageal perforations controversy persists among surgeons about the most appropriate surgical approach. In the absence of a stricture thoracic oesophageal perforation presenting early may be treated by repair and drainage of the chest. Our experience leaves us in no doubt, however, that when a stricture is present distal to the thoracic oesophageal perforation the most appropriate course of action is an immediate one or two stage resection and reconstruction-a view supported by many experienced surgeons. ${ }^{1-38917}$ This radical surgical approach has the advantage of treating the immediate crisis due to the perforation and eventually treating the stricture for which the oesophagoscopy was originally performed. Conservative treatment, including closed drainage of the chest (the "drain and hope" policy ${ }^{17}$ ), was unsuccessful in all such cases in our series. In patients with lower thoracic oesophageal perforation an alternative to resection and reconstruction is to repair the oesophagus, dilate the stricture if present and perform a total fundoplication. This was successful in four of the five patients treated in this way.

\section{References}

1 Triggiani E, Belsey R. Oesophageal trauma incidencediagnosis and management. Thorax 1977:32:241-9.

2 Sandrasagra FA, English TAH, Milstein BB. The management and prognosis of oesophageal perforation. $\mathrm{Br}$ J Surg 1978;65:629-32.

3 Skinner DB, Little AG, DeMeester TR. Management of oesophageal perforation. Am J Surg 1980;139:760-4.

4 Dawson J, Cockel R. Oesophageal perforation at fibreoptic gastroscopy. Br Med J 1981;283:583.

5 Goldstein LA, Thompson WR. Esophageal perforations-a 15 year experience. Am J Surg 1982:143: 495-503.

6 Wesdorp ICE, Bartelsman JFWM. Huibregtse K. et al. Treatment of instrumental oesophageal perforation. Gut 1984:25:398-404.

7 Richardson JD, Martin LF, Borzotta AP. Polk HC. Unifying concepts in treatment of esophageal leaks. Am J Surg 1985;149:157-62.

8 Brewer LA. Carter R, Mulder GA. Stiles QR. Options in the management of perforations of the esophagus. $\mathrm{Am}$ J Surg 1986;152:62-9.

9 Luc M, Grillo HC, Malt RA. Operative and nonoperative management of esophageal perforations. Ann Surg 1981;July:57-63.

10 Ajalat GM, Mulder DG. Esophageal perforations. The need for an individualized approach. Arch Surg 1984;119:1318-20. 
11 Moghissi K. A technique of superior vena caval catheterisation for prolonged intravenous feeding. $J R$ Coll Surg Edinb 1979;2:178-9.

12 Moghissi K, Dietel M, Taylor GA. Oesophageal problems: Use of nutritional support. In: Dietel M, ed. Nutrition in clinical surgery. 2nd ed. Baltimore: Williams and Wilkins, 1985: 303-19.

13 Froggat DL, Gunning AJ. Treatment of oesophageal perforations. Thorax 1966;21:524-8.

14 Craddock DR, Logan A, Myell M. Traumatic rupture of the oesophagus and stomach. Thorax 1968;23:657-62.
15 Anonymous. The leaking oesophagus [editorial]. Lancet 1977;ii:692-3.

16 Hine $\mathrm{KR}$, Atkinson $\mathrm{M}$. The diagnosis and management of perforations of esophagus and pharynx sustained during intubation of neoplastic esophageal strictures. Digestive Diseases and Sciences 1986;31:571-3.

17 Keen G. The surgical management of old esophageal perforations. J Thorac Cardiovasc Surg 1968;56:603-6.

18 Urschel HC, Razzuk MA, Wood RE, Galbraith N, et al. Improved management of esophageal perforation. Ann Surg 1974;179:587-91. 